Article

\title{
Optimization of Microwave Coupled Hot Air Drying for Chinese Yam Using Response Surface Methodology
}

\author{
Hanyang Wang ${ }^{1,2}$, Dan Liu ${ }^{1,2}$, Haiming Yu ${ }^{1,3}$, Donghai Wang ${ }^{2}$ and Jun Li 2,*(D) \\ 1 College of Engineering, Heilongjiang Bayi Agricultural University, Daqing 163319, China; \\ michaelyang198217@163.com (H.W.); ld_wangqi@163.com (D.L.); yhm1973@163.com (H.Y.) \\ 2 Department of Biological and Agricultural Engineering, Kansas State University, Manhattan, KS 66502, USA; \\ dwang@ksu.edu \\ 3 College of Electrical and Information, Northeast Agricultural University, Harbin 150006, China \\ * Correspondence: lijun1989730@ksu.edu; Tel.: +1-785-317-4514
}

Received: 26 September 2019; Accepted: 14 October 2019; Published: 15 October 2019

\begin{abstract}
The effect of microwave coupled hot air drying on rehydration ratio (RR) and total sugar content (TSC) of Chinese yam was investigated. Single factor test and response surface methodology were used for process parameter optimization with hot air temperature, hot air velocity, slice thickness, and microwave power density as variables and RR and TSC of dried products as responses. The effect of variables on RR followed the order: slice thickness $>$ hot air temperature $>$ microwave power density $>$ hot air velocity. The effect of variables on TSC followed the order: slice thickness $>$ microwave power density $>$ hot air velocity $>$ hot air temperature. The optimized process parameters were hot air velocity of $2.5 \mathrm{~m} / \mathrm{s}$, hot air temperature of $61.7^{\circ} \mathrm{C}$, slice thickness of $8.5 \mathrm{~mm}$, and microwave power density of $5.9 \mathrm{~W} / \mathrm{g}$. Under the optimal conditions, the predicted values of RR and TSC were $1.90 \mathrm{~g} / \mathrm{g}$ and $5.74 \mathrm{~g} / 100 \mathrm{~g}$, respectively, which is very close to corresponding actual values $(1.83 \mathrm{~g} / \mathrm{g}$ and $5.72 \mathrm{~g} / 100 \mathrm{~g})$. The desirability of 0.913 further validated the effectiveness of the model. The findings from this work may apply to other agricultural products.
\end{abstract}

Keywords: Chinese yam; microwave coupled hot air; process optimization; rehydration ratio; total sugar content

\section{Introduction}

Chinese yam is an edible food and also an herbal medicinal ingredient [1,2]. Chinese yam contains starch, protein, polysaccharides, dopamine, flavonoids, amino acids, allantoin, trace elements, and other active ingredients. Chinese yam has functions on prevention and treatment of diabetes and digestive system diseases as well as the improvement of human immune system [3,4]. However, same as other vegetables and fruits, fresh Chinese yam is easily damaged during the harvest and transportation because of its crispness and high moisture content, which shortens its shelf life. Fresh Chinese yam also easily gets molded during room temperature storage due to high moisture content, which causes a large amount of nutritional ingredients to be lost and thus lowers its quality and dietary properties [5,6]. To address these issues, drying is usually used to reduce the moisture content lower than a certain threshold value [7]. Dried yam can be used as an important component in Chinese traditional medicine or important ingredients in various food products such as candies, cakes, and soft drinks. However, the drying process can cause severe chemical and physical changes in the properties of dried materials. As a result, choosing a proper method is very important for drying of Chinese yam.

Recently, many drying methods for fruits and vegetables have been reported such as far-infrared radiation assisted freeze drying [5], hot air drying [2], far-infrared radiation and heat pump drying [8,9], 
microwave freeze drying, microwave vacuum drying [10], and freeze drying, among which hot air drying is the most commonly applied for the postharvest preservation of Chinese yam and other agricultural products because of its simple processing and low-cost equipment. However, during hot air drying, the direction of heat transfer (from the surface of drying materials to the interior) is opposite to that of water transfer, which results in low heat transfer rate, long drying period, and high energy cost [11]. These disadvantages not only affect the color, flavor, texture, taste, and nutrients of dried materials but also reduce the density and water absorbance ability of dried products and the shift of solutes from the interior to the surface [12]. Compared to hot air drying, microwave drying technology is another method that has been widely used to dry various vegetables and fruits because of its high energy efficiency and high drying rate $[13,14]$. It is applicable for the drying of fruit and vegetable products especially with high moisture content (e.g., grape, carrot, and apple). Microwave drying is a volumetric drying method which can enhance heat transfer. In the drying process, the electromagnetic energy with high frequency is absorbed and directly transformed into kinetic energy of water molecules. The interior heat generated by "molecular friction" within the materials leads to water evaporation and subsequently creates a pressure environment with the pressure decreasing from the interior of drying materials to the surface. Thus, the pressure gradient can greatly speed up the drying process, shorten drying period, and improve energy efficiency $[13,15]$. Nevertheless, microwave drying is well known to cause non-uniform heating. The local temperature, especially along the edge and corner, can easily rise to a high level if not properly applied, resulting in gelatinization and off-flavor. In addition, the rapid moisture loss and mass transfer caused by microwave power may lead to the poor quality or the unfavorable structural changes such as puffing [16]. Based on the above analysis, the combination of microwave drying and hot air drying could be a great option to overcome the shortcomings associated with individual microwave drying and hot air drying.

The combination of hot air and microwave can not only reduce the drying time but also improve the final quality of food products. The combination has two forms: one is applying hot air and microwave drying in stages; the other, named as microwave coupled with hot air (MWHA), simultaneously uses the two methods and has been considered as an innovative technique for drying fruits and vegetables [17]. In the MWHA drying process, microwave energy absorbed by the drying materials is directly transformed into heat which can go throughout the drying materials. The moisture is driven by the volumetric heating, traveling from the inside of the drying materials to the surface, and then continuously evaporated by the moving hot air [18]. Therefore, the moisture removal of drying materials is affected by the interaction of hot air and microwave in the MWHA drying process. In the past few years, some studies using the combination of hot air and microwave have been reported for drying food products including soybean [19], potato [20], longan [21], and orange peel [22]. However, up to date, no report has been found on the drying of Chinese yam using MWHA.

Response surface methodology (RSM) has been widely employed to optimize and improve various processes. In multifactor tests, RSM is frequently employed to determine the interactions among tested variables as well as their influence ranges, and regression equations are employed to describe the effects of variables on the response [23-25]. Using this approach, a process or system can be efficiently explored. Therefore, RSM has been successfully applied to optimize the drying processes of okra [26], frozen sour cherries [27], hawthorn [28], quince [24], and olive leaves [25]. In this research, the process optimization of MWHA drying for Chinese yam was investigated using RSM.

The objectives of this research were to determine the main effects of process variables (slice thickness, hot air temperature, microwave power density, and hot air velocity) on the quality of dried Chinese yam as well as to optimize the process parameters during MWHA drying. 


\section{Materials and Methods}

\subsection{Materials}

Fresh Chinese yams with similar shapes and sizes and initial moisture content of 78\% (wet basis) were purchased from a local supermarket. For initial moisture content measurement, the fresh Chinese

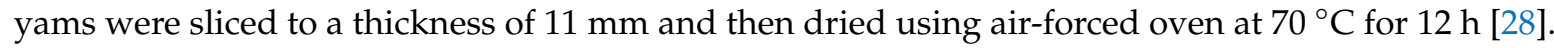
All of the tested Chinese yams were free of disease, mechanical damage, and decay. After being washed and drained, the samples were cut into the designated thicknesses, put into plastic bags, and stored in a freezer at $4 \pm 0.5^{\circ} \mathrm{C}$.

\subsection{Experimental Apparatus}

The MWHA dryer (YHMW900-100) used for this study was fabricated by the Heilongjiang Bayi Agricultural University (Daqing, China) (Figure 1).

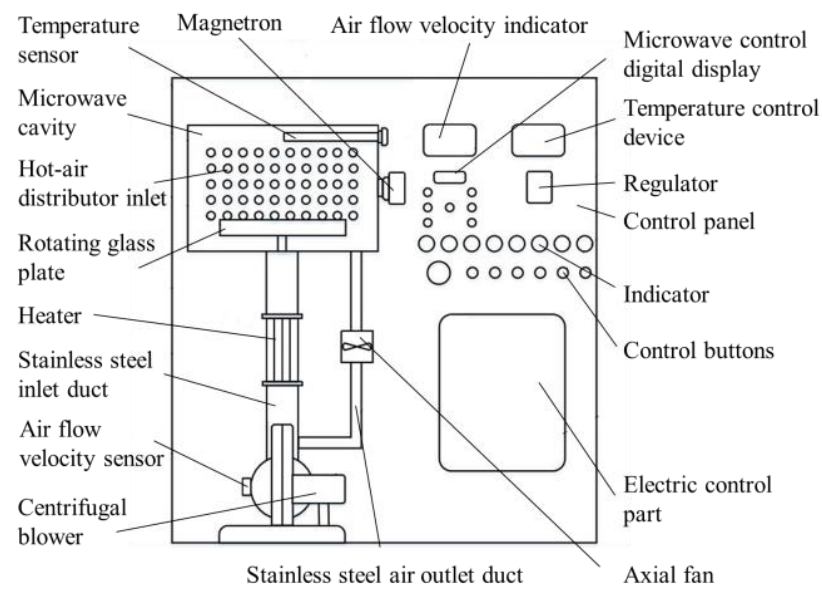

Figure 1. Schematic diagram of microwave coupled with hot air (MWHA) dryer.

The MWHA dryer which can be found in our previous paper mainly contains two drying systems: hot air and microwave [28]. In the hot-air drying system, the hot air velocity and hot air temperature are in the ranges of $0-5 \mathrm{~m} / \mathrm{s}$ and $30-100{ }^{\circ} \mathrm{C}$, respectively. The microwave input power of the microwave drying system is $1300 \mathrm{~W}$, and the output power can be adjusted to 180-900 W with the interval of $180 \mathrm{~W}$. The drying time can be controlled in the range of 0-180 $\mathrm{min}$.

The mass change of the tested samples was measured using a digital balance (American Twin Brothers Co. Ltd., model T100, Shanghai, China) with a precision of $0.01 \mathrm{~g}$.

\subsection{Experimental Procedure}

Fresh yams were cut into designated thicknesses with an approximately $60 \mathrm{~mm}$ diameter using a shelf-style sharp food slicer. Before each test, the hot air drying system was run 10-20 min to stabilize the hot air in microwave cavity at target temperature. The yam slices with the required thicknesses and weights were distributed uniformly on a plastic tray in the manner of thin layer, followed by putting into the microwave cavity and starting the microwave drying system. The tested sample weight was measured every $60 \mathrm{~s}$ during the drying process. Once the moisture content of dried Chinese yam slices reached around $8.0 \%$ (dry basis), the drying process was terminated. All experiments were conducted in triplicate. Dried samples were cooled down under ambient temperature for $10 \mathrm{~min}$, followed by packing into plastic bags and storing in a freezer at $4 \pm 0.5^{\circ} \mathrm{C}$ for rehydration ratio (RR) and total sugar content (TSC) evaluation. 


\subsection{Determination of $R R$}

$\mathrm{RR}$, which represents the physical and chemical changes of dried products and capacity of being rehydrated before their final use, was evaluated by soaking $10 \mathrm{~g}$ of the dried Chinese yam slices in $300 \mathrm{~mL}$ of distilled water at $80^{\circ} \mathrm{C}$ for $20 \mathrm{~min}$ [29]. After soaking, superficial water was removed by placing the samples on a fiber glass wire mesh for $3 \mathrm{~min}$ and then the samples were weighed. $R R$ was calculated using Equation (1) [30,31]:

$$
\mathrm{RR}=\frac{\mathrm{W}_{1}-\mathrm{W}_{2}}{\mathrm{~W}_{2}}
$$

where RR is the rehydration ratio of the dried yam slices, $g / g ; W_{1}$ is the weight of the sample after rehydration, $\mathrm{g} ; \mathrm{W}_{2}$ is the weight of the sample before rehydration, $\mathrm{g}$.

\subsection{Determination of TSC}

TSC was measured according to GB/T 10782-2006 [32]. After milling to fine powders, $10 \mathrm{~g}$ of each dried yam was soaked in $200 \mathrm{~mL}$ of distilled water for $2 \mathrm{~h}$. The slurries were transferred in $250 \mathrm{~mL}$ volumetric flasks and then diluted to $250 \mathrm{~mL}$. After that, the slurries were filtered to collect the filtrates. Ten milliliter of each filtrate, $30 \mathrm{~mL}$ of distilled water, $5 \mathrm{~mL}$ of hydrochloric acid $(37 \%, v / v)$ were loaded in $250 \mathrm{~mL}$ flasks, heated to $68-70{ }^{\circ} \mathrm{C}$ and kept for $10 \mathrm{~min}$, and then cooled down to room temperature. The filtrates were transferred in $250 \mathrm{~mL}$ volumetric flasks, followed by the addition of 2 drops of methyl red indicator $(0.001 \mathrm{~g} / \mathrm{L})$. The filtrates were then neutralized by sodium hydroxide $(0.3 \mathrm{~g} / \mathrm{L})$ and diluted to $250 \mathrm{~mL}$. The neutralized filtrates were individually used to titrate the standard Fehling reagent $(10 \mathrm{~mL})$ and the consumed volumes of the filtrates were recorded to calculate TSC using Equation (2) [33]:

$$
\mathrm{TSC}=\frac{\mathrm{A} \times 6250}{\mathrm{~W}_{3} \times \mathrm{V}} \times 100
$$

where TSC is total sugar content in the sample, $\mathrm{g} / 100 \mathrm{~g} ; 6250$ is the dilution ratio; $\mathrm{W}_{3}$ is the weight of the sample, g; $\mathrm{A}$ is $10 \mathrm{~mL}$ of Fehling reagent that equals to the glucose quality, $\mathrm{g}$; $\mathrm{V}$ is the volume of the test solution consumed during the titration, $\mathrm{mL}$.

\subsection{Experimental Design, Statistical Analysis, and Optimization}

In this study, process variables slice thickness $\left(S_{t}\right)$, hot air velocity $\left(H_{v}\right)$, hot air temperature $\left(H_{t}\right)$, and microwave power density $\left(M_{d}\right)$ were represented with codes $x_{1}, x_{2}, x_{3}$, and $x_{4}$. Single factor experiments were first conducted to determine the rational ranges of variables in preparation for RSM experiments. The process variables and levels used in single factor experiments are shown in Table 1.

Table 1. Variables and levels in single factorial design.

\begin{tabular}{cccccccc}
\hline Variables & \multicolumn{7}{c}{ Levels } \\
\hline Slice Thickness $/ S_{t}(\mathrm{~mm})$ & 4.0 & 6.0 & 8.0 & 10.0 & 12.0 & 14.0 & 16.0 \\
Hot air velocity $/ H_{v}(\mathrm{~m} / \mathrm{s})$ & 1.5 & 2.0 & 2.5 & 3.0 & 3.5 & 4.0 & 4.5 \\
Hot air temperature $/ H_{t}\left({ }^{\circ} \mathrm{C}\right)$ & 45.0 & 50.0 & 55.0 & 60.0 & 65.0 & 70.0 & 75.0 \\
Microwave power density $/ \mathrm{M}_{d}(\mathrm{~W} / \mathrm{g})$ & 3.0 & 4.0 & 5.0 & 6.0 & 7.0 & 8.0 & 9.0 \\
\hline
\end{tabular}

Based on the results from single factor experiments, the relative contributions of variables to the responses RR and TSC were determined using RSM. A central composite rotatable design was employed to investigate the optimal conditions of MWHA drying process, and 31 experiments with 7 replicates at the center point were carried out. The experimental variables and levels used in the RSM design are listed in Table 2. 
Table 2. The independent variables and levels for the Response surface methodology (RSM) design.

\begin{tabular}{ccccccc}
\hline \multirow{2}{*}{ Independent Variables } & \multirow{3}{*}{ Symbols } & \multicolumn{5}{c}{ Levels } \\
\cline { 3 - 7 } & & $\mathbf{- 2}$ & $\mathbf{- 1}$ & $\mathbf{0}$ & $\mathbf{+ 1}$ & $\mathbf{+ 2}$ \\
\hline Slice thickness $/ S_{t}(\mathrm{~mm})$ & $x_{1}$ & 6.0 & 8.0 & 10.0 & 12.0 & 14.0 \\
Hot-air velocity $/ H_{v}(\mathrm{~m} / \mathrm{s})$ & $x_{2}$ & 1.5 & 2.0 & 2.5 & 3.0 & 3.5 \\
Hot-air temperature $/ H_{t}\left({ }^{\circ} \mathrm{C}\right)$ & $x_{3}$ & 50.0 & 55.0 & 60.0 & 65.0 & 70.0 \\
Microwave power density $/ M_{d}(\mathrm{~W} / \mathrm{g})$ & $x_{4}$ & 2.0 & 4.0 & 6.0 & 8.0 & 10.0 \\
\hline
\end{tabular}

Due to the extraneous factors, all of the experiments were randomized with the purpose of minimizing the effects of unexplained variability on the observed responses. The experimental data was analyzed using a statistical software Design Expert with the version of 8.0.5b, and RSM was performed to obtain 3D surface graphs between variables and response.

The following second-order polynomial of Equation (3) was applied to fit the experimental data [34,35]:

$$
\mathrm{y}=\beta_{0}+\sum_{i=1}^{k} \beta_{i} x_{i}+\sum_{i=1}^{k} \beta_{i i} x_{i}^{2}+\sum \sum_{i<j=1}^{k} \beta_{i j} x_{i} x_{j}
$$

where $y$ values are investigated responses (RR and TSC); $\beta_{0}, \beta_{i}, \beta_{i i}$, and $\beta_{i j}$ are constant regression coefficients of intercept, linear, quadratic, and interaction terms, respectively; $x_{i}$ and $x_{j}$ are the coded independent variables.

At the significance level of $p=0.05$, the analysis of variance (ANOVA) was used to statistically test the experimental results. In addition, $p$ value and the coefficient of determination $\left(R^{2}\right)$ was employed to evaluate the adequacy of the model [36].

Several response variables are normally optimized to describe the system performance and quality characteristics during the optimization of various industrial processes. Some of these response variables require being minimized while others require being maximized. Under certain circumstances, these response variables are competitive, that is, when changing one response, the opposite effect may yield on another one, which makes the situation more complicated. Usually, three ways can be employed to solve the problem. Desirability function is the most common method to solve the problem [25].

Specific steps for optimizing the desirable functions are as following: (1) making response variables dimensionless, (2) determining weighting coefficient, (3) constructing desirability function and solution, (4) optimizing the model using the fuzzy similar preceding ratio method [37].

In this work, desirability function was developed with maximizing RR and TSC as the criteria.

\section{Results and Discussion}

\subsection{Single Factorial Experiment}

\subsubsection{Effects of Independent Variables on RR}

The effects of process variables $\left(S_{t}, H_{v}, H_{t}\right.$, and $\left.M_{d}\right)$ on RR of dried yam products are shown in Figure 2. RR increased first and then decreased when the slice thickness is $10 \mathrm{~mm}$, microwave power density is $6 \mathrm{~W} / \mathrm{g}$, and the velocity and temperature of hot air are $2.5 \mathrm{~m} / \mathrm{s}$ and $60^{\circ} \mathrm{C}$, respectively. Based on the results, the value ranges of process variables that are suitable for the RSM can be confirmed as slice thickness of $8-12 \mathrm{~mm}$, hot-air velocity and temperature of $2.0-3.0 \mathrm{~m} / \mathrm{s}$ and $55-65{ }^{\circ} \mathrm{C}$, and microwave power density of 5-7 W/g with the principle of maximizing RR. 


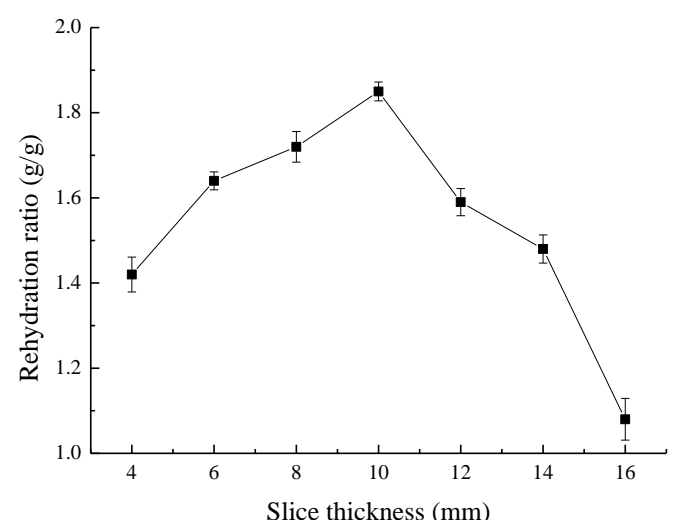

(a)

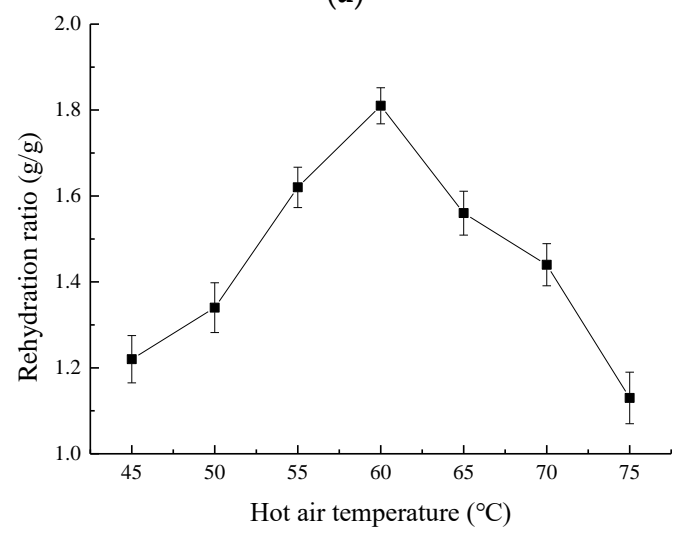

(c)

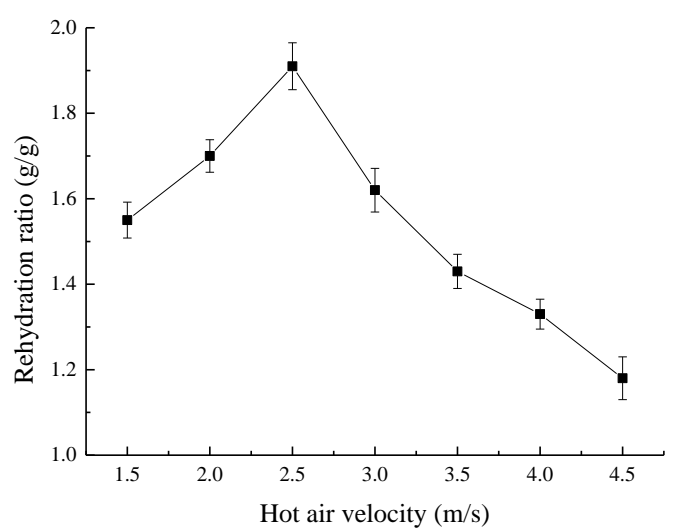

(b)

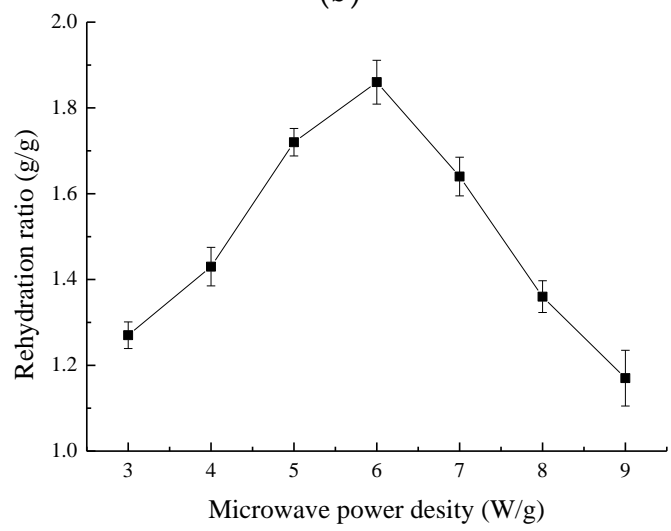

(d)

Figure 2. The effects of independent variables on rehydration ratio (RR). (a) Effect of slice thickness of yam slices on RR; (b) Effect of hot air velocity on RR; (c) Effect of hot air temperature on RR; (d) Effect of microwave power density on RR.

\subsubsection{Effects of Independent Variables on TSC}

The effects of process variables on TSC of dried yam products are shown in Figure 3. TSC decreased as slice thickness increased. However, TSC increased first and then decreased at the hot air temperature of $60^{\circ} \mathrm{C}$, microwave power density of $6 \mathrm{~W} / \mathrm{g}$, and hot air velocity of $2.5 \mathrm{~m} / \mathrm{s}$. Consequently, according to the criteria of maximizing TSC, the rational value ranges of process variables for the RSM can be identified as slice thickness of more than $4 \mathrm{~mm}$, microwave power density of $5-7 \mathrm{~W} / \mathrm{g}$, hot-air velocity and temperature of $2.0-3.0 \mathrm{~m} / \mathrm{s}$ and $55-65^{\circ} \mathrm{C}$, respectively.

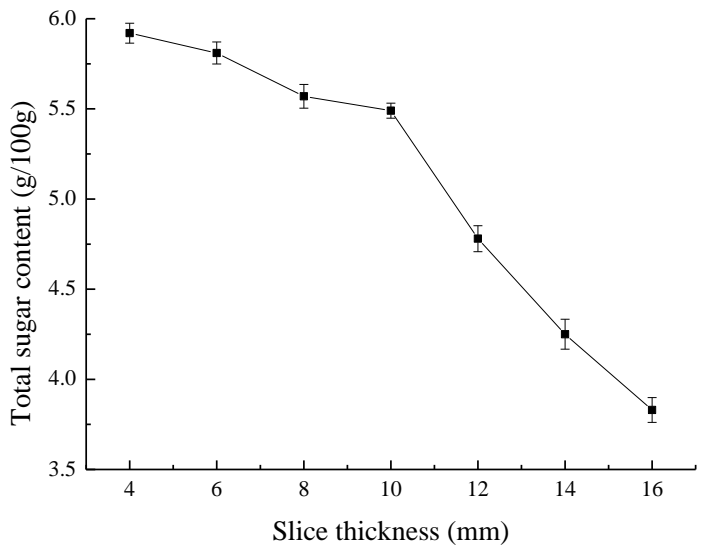

(a)

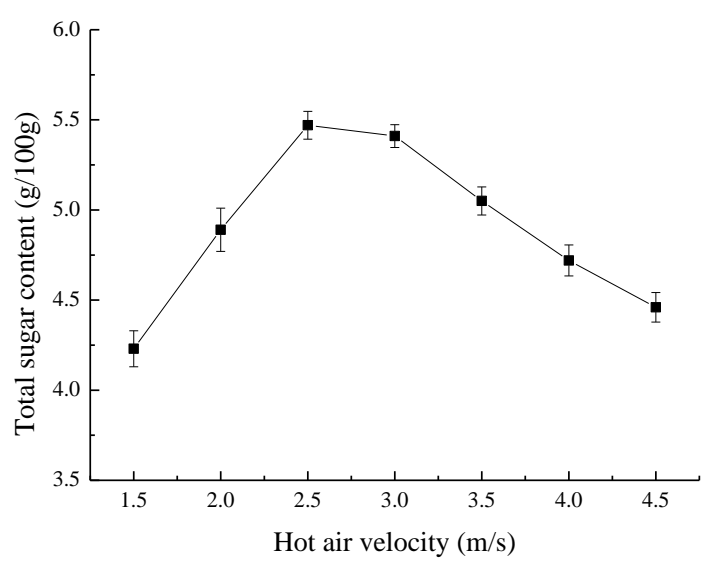

(b)

Figure 3. Cont. 


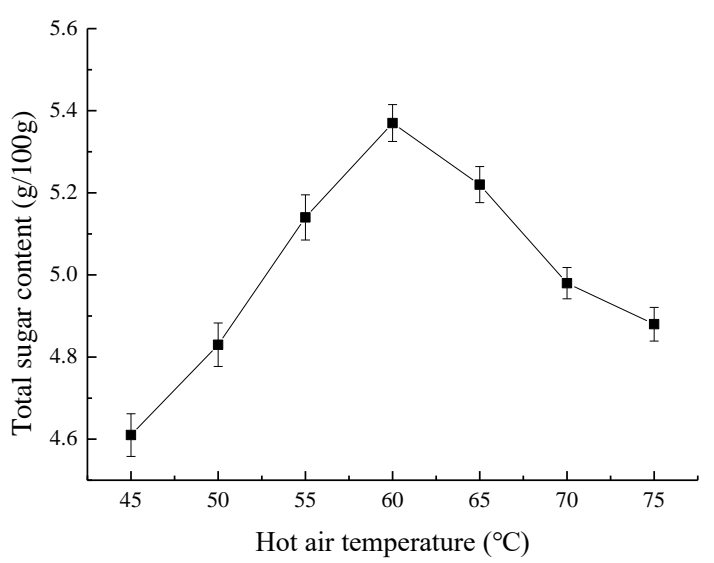

(c)

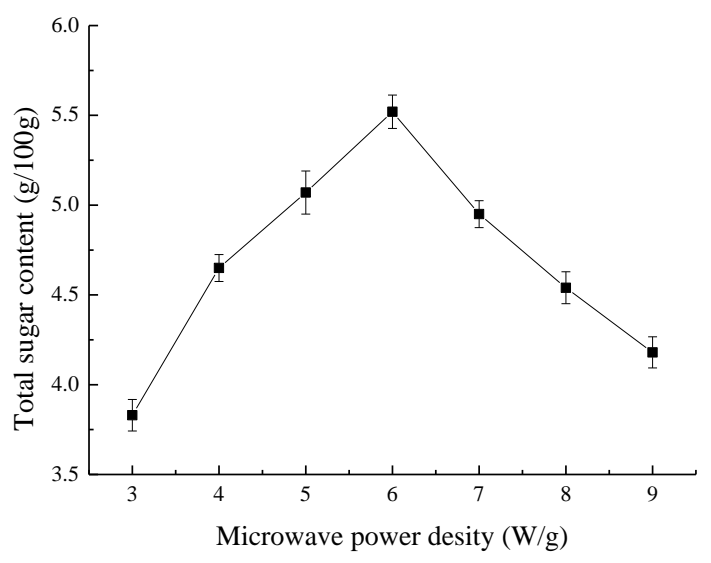

(d)

Figure 3. The effects of independent variables on total sugar content (TSC). (a) Effect of slice thickness of yam slices on TSC; (b) Effect of hot-air velocity on TSC; (c) Effect of hot-air temperature on TSC; (d) Effect of microwave power density on TSC.

Based on the comprehensive consideration regarding the single factor experiment results, the values of process variables at zero level for RSM were finally determined to be slice thickness of $10 \mathrm{~mm}$, microwave power density of $6 \mathrm{~W} / \mathrm{g}$, hot air velocity and temperature of $2.5 \mathrm{~m} / \mathrm{s}$ and $60{ }^{\circ} \mathrm{C}$, respectively.

\subsection{RSM Experiment}

Experimental design of RSM is listed in Table 3. By conducting ANOVA, the significant effects of all process variables on each response was determined and the experimental data was fitted to second-order polynomial models (Table 4).

Table 3. Experimental design and RR and TSC values from response surface analysis.

\begin{tabular}{|c|c|c|c|c|c|c|}
\hline \multirow{2}{*}{ Run } & \multicolumn{4}{|c|}{ Variable Levels } & \multirow{2}{*}{$\mathrm{RR}, y_{1}(\mathrm{~g} / \mathrm{g})$} & \multirow{2}{*}{ TSC, $y_{2}(\mathrm{~g} / \mathbf{1 0 0 g})$} \\
\hline & $x_{1}$ & $x_{2}$ & $x_{3}$ & $x_{4}$ & & \\
\hline 1 & -1 & -1 & -1 & -1 & 1.57 & 4.25 \\
\hline 2 & 1 & -1 & -1 & -1 & 1.24 & 3.75 \\
\hline 3 & -1 & 1 & -1 & -1 & 1.21 & 5.01 \\
\hline 4 & 1 & 1 & -1 & -1 & 1.02 & 4.12 \\
\hline 5 & -1 & -1 & 1 & -1 & 1.82 & 4.87 \\
\hline 6 & 1 & -1 & 1 & -1 & 1.56 & 4.03 \\
\hline 7 & -1 & 1 & 1 & -1 & 1.65 & 5.19 \\
\hline 8 & 1 & 1 & 1 & -1 & 1.31 & 4.52 \\
\hline 9 & -1 & -1 & -1 & 1 & 1.33 & 5.17 \\
\hline 10 & 1 & -1 & -1 & 1 & 1.02 & 4.13 \\
\hline 11 & -1 & 1 & -1 & 1 & 1.22 & 5.43 \\
\hline 12 & 1 & 1 & -1 & 1 & 1.02 & 4.39 \\
\hline 13 & -1 & -1 & 1 & 1 & 1.34 & 5.48 \\
\hline 14 & 1 & -1 & 1 & 1 & 1.18 & 4.52 \\
\hline 15 & -1 & 1 & 1 & 1 & 1.25 & 5.55 \\
\hline 16 & 1 & 1 & 1 & 1 & 1.16 & 4.61 \\
\hline 17 & -2 & 0 & 0 & 0 & 1.52 & 5.89 \\
\hline 18 & 2 & 0 & 0 & 0 & 1.01 & 3.75 \\
\hline 19 & 0 & -2 & 0 & 0 & 1.55 & 4.25 \\
\hline 20 & 0 & 2 & 0 & 0 & 1.33 & 5.02 \\
\hline 21 & 0 & 0 & -2 & 0 & 1.26 & 4.86 \\
\hline
\end{tabular}


Table 3. Cont.

\begin{tabular}{|c|c|c|c|c|c|c|}
\hline \multirow{2}{*}{ Run } & \multicolumn{4}{|c|}{ Variable Levels } & \multirow{2}{*}{$R R, y_{1}(g / g)$} & \multirow{2}{*}{ TSC, $y_{2}(\mathrm{~g} / 100 \mathrm{~g})$} \\
\hline & $x_{1}$ & $x_{2}$ & $x_{3}$ & $x_{4}$ & & \\
\hline 22 & 0 & 0 & 2 & 0 & 1.43 & 4.95 \\
\hline 23 & 0 & 0 & 0 & -2 & 1.18 & 3.65 \\
\hline 24 & 0 & 0 & 0 & 2 & 1.16 & 4.13 \\
\hline 25 & 0 & 0 & 0 & 0 & 1.96 & 5.69 \\
\hline 26 & 0 & 0 & 0 & 0 & 2.01 & 5.52 \\
\hline 27 & 0 & 0 & 0 & 0 & 1.83 & 5.29 \\
\hline 28 & 0 & 0 & 0 & 0 & 1.84 & 5.61 \\
\hline 29 & 0 & 0 & 0 & 0 & 1.79 & 5.45 \\
\hline 30 & 0 & 0 & 0 & 0 & 1.92 & 5.39 \\
\hline 31 & 0 & 0 & 0 & 0 & 1.85 & 5.22 \\
\hline
\end{tabular}

Table 4. ANOVA evaluation of linear, quadratic, and interaction terms for each response variable and coefficient of prediction models.

\begin{tabular}{|c|c|c|c|c|c|c|c|}
\hline \multirow[b]{2}{*}{ Source } & \multirow[b]{2}{*}{ df } & \multicolumn{3}{|c|}{$\mathbf{R R}$} & \multicolumn{3}{|c|}{ TSC } \\
\hline & & Coefficient & $\begin{array}{l}\text { Sum of } \\
\text { Squares }\end{array}$ & $p$-Value & Coefficient & $\begin{array}{l}\text { Sum of } \\
\text { Squares }\end{array}$ & $p$-Value \\
\hline Model & 14 & 1.89 & 2.79 & $<0.0001$ & 5.45 & 12.08 & $<0.0001$ \\
\hline$x_{1}$ & 1 & -0.12 & 0.35 & $<0.0001$ & -0.47 & 5.19 & $<0.0001$ \\
\hline$x_{2}$ & 1 & -0.069 & 0.11 & 0.0024 & 0.17 & 0.72 & 0.0002 \\
\hline$x_{3}$ & 1 & 0.082 & 0.16 & 0.0006 & 0.11 & 0.3 & 0.0075 \\
\hline$x_{4}$ & 1 & -0.079 & 0.15 & 0.0008 & 0.19 & 0.84 & 0.0001 \\
\hline$x_{1} x_{2}$ & 1 & 0.015 & 0.0036 & 0.5331 & -0.013 & 0.0025 & 0.7848 \\
\hline$x_{1} x_{3}$ & 1 & 0.011 & 0.002 & 0.6392 & 0.00375 & 0.000225 & 0.9346 \\
\hline$x_{1} x_{4}$ & 1 & 0.023 & 0.0081 & 0.3535 & -0.068 & 0.073 & 0.1532 \\
\hline$x_{2} x_{3}$ & 1 & 0.01 & 0.0016 & 0.6767 & -0.043 & 0.029 & 0.3592 \\
\hline$x_{2} x_{4}$ & 1 & 0.049 & 0.038 & 0.0549 & -0.079 & 0.099 & 0.0994 \\
\hline$x_{3} x_{4}$ & 1 & -0.06 & 0.058 & 0.0215 & -0.028 & 0.012 & 0.5499 \\
\hline$x_{1}^{2}$ & 1 & -0.15 & 0.69 & $<0.0001$ & -0.14 & 0.54 & 0.0009 \\
\hline$x_{2}^{\frac{1}{2}}$ & 1 & -0.11 & 0.35 & $<0.0001$ & -0.18 & 0.96 & $<0.0001$ \\
\hline$x_{3}^{2}$ & 1 & -0.13 & 0.52 & $<0.0001$ & -0.12 & 0.38 & 0.0033 \\
\hline$x_{4}^{2}$ & 1 & -0.18 & 0.91 & $<0.0001$ & -0.37 & 3.91 & $<0.0001$ \\
\hline Residual & 16 & & 0.14 & & & 0.52 & \\
\hline Lack of fit & 10 & & 0.1 & 0.2779 & & 0.35 & 0.4169 \\
\hline Pure error & 6 & & 0.038 & & & 0.17 & \\
\hline Total & 30 & & 2.93 & & & 12.6 & \\
\hline$R^{2}$ & & 0.9516 & & & 0.9588 & & \\
\hline $\mathrm{CV} / \%$ & & 6.55 & & & 3.73 & & \\
\hline
\end{tabular}

Note: CV means coefficient of variation.

Table 4 indicates that the two regression models for RR and TSC were observed to be statistically significant at $1 \%$ level of significance $(p \leq 0.01)$, indicating that the experimental data were consistent with the second-order polynomial response surface models and the predicted models $y_{1}$ and $y_{2}$ could well fit the actual situation. The $R^{2}$ values of the two prediction models were 0.9516 and 0.9588 for RR and TSC, respectively, demonstrating that the experimental values can be reasonably represented by the prediction models. Therefore, the responses could be sufficiently explained by the models [38]. Meanwhile, the values of coefficient of variation (CV) were $6.55 \%$ for RR and $3.73 \%$ for TSC, which are less than $10 \%$, indicating that the variation of the test values was within a rational range [39]. Table 4 also shows that the $p$-values of the lack of fit were 0.2779 and 0.4169 , which were not statistically significant at $5 \%$ level, indicating that the prediction models were adequately accurate for predicting these responses. 


\subsubsection{Analysis of RR}

RR was in the range of $1.01-2.01 \mathrm{~g} / \mathrm{g}$ under various conditions (Table 3). According to ANOVA results (Table 4$)$, all of the drying parameters $\left(S_{t}, H_{v}, H_{t}\right.$, and $\left.M_{d}\right)$ had extremely significant effects on $R R(p \leq 0.01)$. The $p$-values of variables indicate that slice thickness had the most effect on RR, followed by hot air temperature, microwave power density, and hot air velocity. Thus, slice thickness was a major factor that influenced the rehydration attribute of dried yam slices. However, the effects of all the interaction terms on RR were not statistically significant $(p \geq 0.05)$ except for the interaction effect of hot air temperature and microwave power density at statistical level of $p \leq 0.05$. The quadratic level of all the process variables had significant effects on RR at statistical level of $p \leq 0.01$. By removing the statistically insignificant items of $x_{1} x_{2}, x_{1} x_{3}, x_{1} x_{4}, x_{2} x_{3}, x_{2} x_{4}$ at the level of $\alpha=5 \%$, Equation (4) was given with $R^{2}$ of 0.9516 , indicating a good model fit.

$$
\begin{gathered}
\mathrm{RR}=-25.057+0.576 S_{t}+1.404 H_{v}+0.679 H_{t}+0.679 M_{d}-0.006 H_{t} M_{d}-0.039 S_{t}^{2} \\
-0.445 H_{v}^{2}-0.006 H_{t}^{2}-0.045 M_{d}^{2}
\end{gathered}
$$

To intuitively understand the combined effects of each two variables on RR, the response surface and contour plots were plotted for each of the fitted models as the function of two independent variables while other variables were kept at central values (Figure 4).
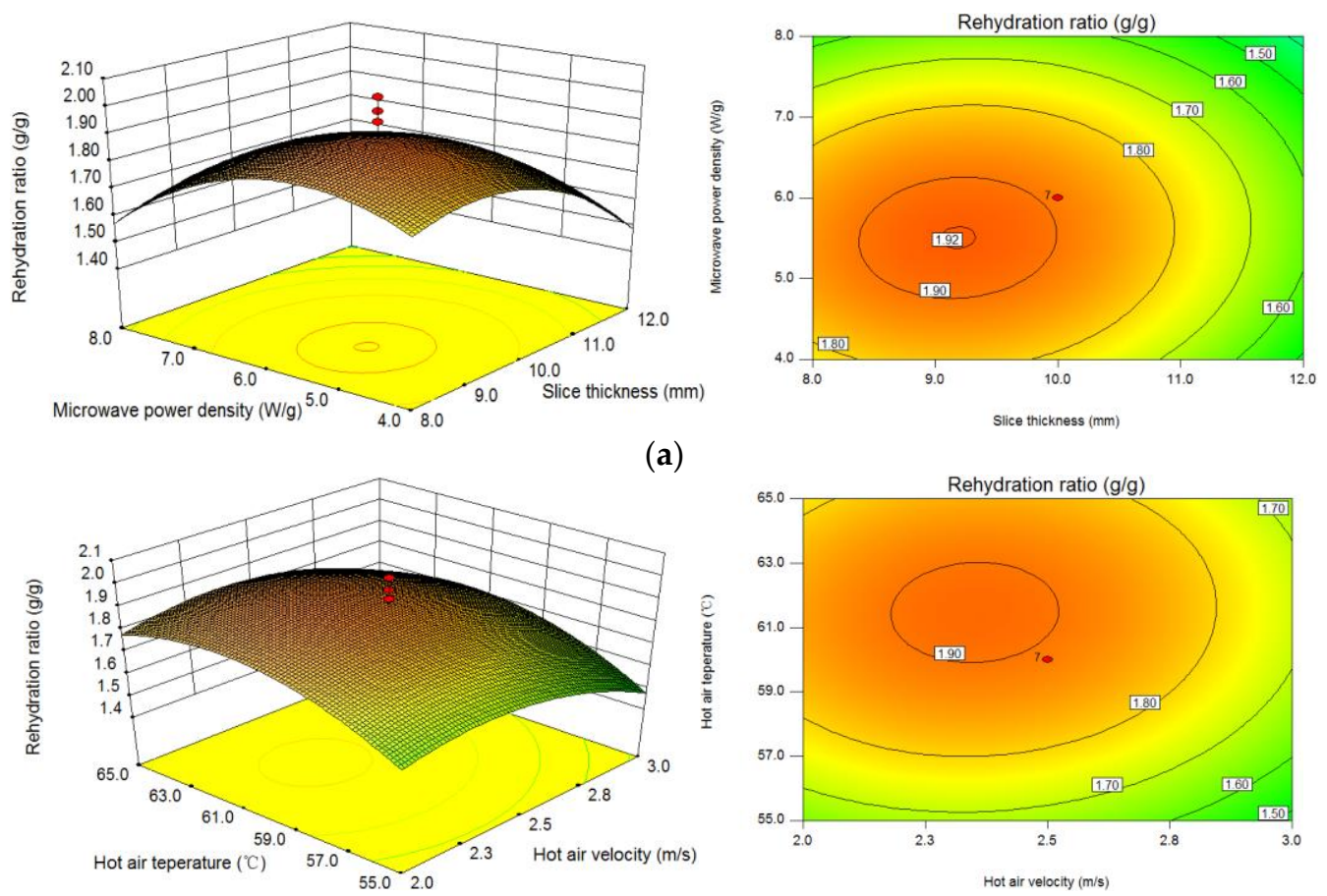

(b)

Figure 4. Response surface plots of RR between variables. (a) Slice thickness and microwave power density; (b) Hot air velocity and hot air temperature.

Figure 4a shows the interaction effect of slice thickness and microwave power density on RR with constant hot air velocity and hot air temperature at $2.5 \mathrm{~m} / \mathrm{s}$ and $60^{\circ} \mathrm{C}$, respectively. When slice thickness was less than $10 \mathrm{~mm}$ and microwave power density was lower than $6 \mathrm{~W} / \mathrm{g}$, the correlation between $\mathrm{RR}$ and the variables was positive. RR could reach up to a level higher than $1.9 \mathrm{~g} / \mathrm{g}$ at slice thickness and microwave power density ranging from 6 to $10 \mathrm{~mm}$ and 2 to $6 \mathrm{~W} / \mathrm{g}$, respectively. This behavior is because when the slice thickness was at a thinner level, the rate of water transfer from the interior of drying Chinese yam slices to the surface was much faster than that of water evaporation on the surface, which resulted in a sharp rise in the temperature of the interior of drying materials and then caused 
volume shrinkage and case hardening, subsequently decreasing the rehydration capacity of dried yam slices. RR increased as slice thickness gradually increased to a certain level, which is probably because water transfer and evaporation rates tended to be balanced with the increase of slice thickness. However, the balance was disrupted when slice thickness was thicker than $10 \mathrm{~mm}$, leading to lower rehydration properties. A similar result was reported in the study of microwave-vacuum drying for button mushroom [38]. The high RR at high microwave power density may be due to the formation of high pressure in the interior of drying yams caused by high microwave power density. The interior water rapidly evaporated with the quick absorption of microwave energy and thus generated many pores in the interior of drying yams, which benefited in preventing the volume shrinkage and case hardening of dried yams, thereby, enhancing RR. This finding is consistent with a previous study [40]. Nevertheless, RR decreased when microwave power density exceeded $6 \mathrm{~W} / \mathrm{g}$, which is due to the damage of cellular structures caused by excessive power density [41].

Figure $4 \mathrm{~b}$ represents that the relationship between RR and hot air velocity and hot air temperature was a quadratic function. RR increased first and then decreased at hot air velocity and temperature of $2.5 \mathrm{~m} / \mathrm{s}$ and $60^{\circ} \mathrm{C}$ [24], respectively, which demonstrates that the increase of hot air temperature and velocity at low levels could promote the evaporation rate of water on the surface and enhance the pressure gradient between the interior and the surface of drying materials. The enhanced pressure gradient contributed to the rapid escape of water from the interior to the surface and formed some capillary channels, which benefited by improving RR. However, when hot air velocity and temperature exceeded rational ranges $\left(H_{v} \geq 2.5 \mathrm{~m} / \mathrm{s}\right.$ and $\left.H_{t} \geq 60^{\circ} \mathrm{C}\right)$, the excessive dehydration led to structure destruction, severe volume shrinkage, and case hardening, thus worsening rehydration characteristics.

\subsubsection{Analysis of TSC}

As shown in Table 3, TSC of dried yam slices ranged from 3.65 to $5.89 \mathrm{~g} / 100 \mathrm{~g}$ under various conditions. For the linear items, all process variables were significant in the model $(p \leq 0.01$, Table 4$)$. The $p$-values of each variable illustrated that slice thickness had the most effect on TSC, followed by microwave power density, hot air velocity, and hot air temperature. Thus, slice thickness was a major factor that influenced the TSC of dried yam slices. According to the $p$-values, all of the interaction effects were not statistically significant $(p \geq 0.05)$, while their quadratic levels were significant $(p \leq 0.01)$. By removing the statistically insignificant items of $x_{1} x_{2}, x_{1} x_{3}, x_{1} x_{4}, x_{2} x_{3}, x_{2} x_{4}, x_{3} x_{4}$ at the level of $\alpha=5 \%$, Equation (5) was given with $R^{2}$ of 0.9588 , indicating a good model fit.

$$
\begin{aligned}
\mathrm{TSC}=-28.857 & +0.563 S_{t}+5.633 H_{v}+0.634 H_{t}+1.733 M_{d}-0.034 S_{t}^{2}-0.734 H_{v}^{2}-0.004 H_{t}^{2} \\
& -0.092 M_{d}^{2}
\end{aligned}
$$

To intuitively understand the combined effects of each two variables on TSC, the response surface and contour plots were also plotted for each of the fitted models as the function of two independent variables while keeping other variables at central values (Figure 5). Figure 5a indicates the interaction effect of slice thickness and microwave power density on TSC with constant hot air velocity and temperature at $2.5 \mathrm{~m} / \mathrm{s}$ and $60{ }^{\circ} \mathrm{C}$, respectively. TSC was negatively correlated with slice thickness, which is because the increase of slice thickness increased the transfer distance of water from the interior to the surface and thus required longer drying time, which increased total sugar loss. However, TSC was positively correlated with microwave power density at the level below $7.0 \mathrm{~W} / \mathrm{g}$, which is because the increased absorption of microwave energy enhanced the evaporation and transfer rates of water, thus effectively shortening drying time and reducing the undesired chemical reactions of sugars themselves as well as sugars with other ingredients. In addition, although the microwave power density of greater than $7.0 \mathrm{~W} / \mathrm{g}$ further shortened drying time, the temperature of drying materials rose sharply, which intensified the Maillard and caramelization reactions of polysaccharides. 

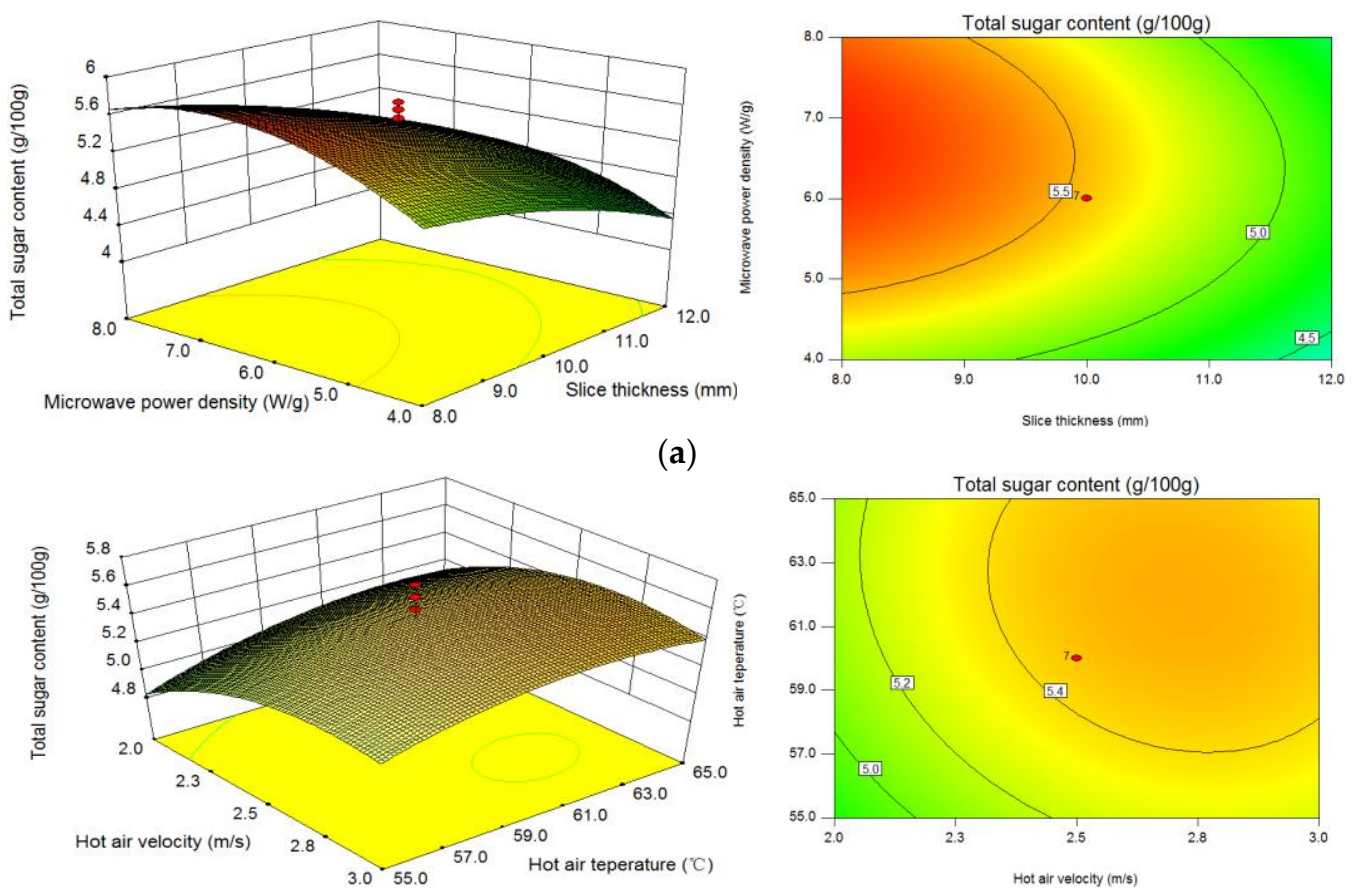

(b)

Figure 5. Response surface plots of TSC between variables. (a) Slice thickness and microwave power density; (b) Hot air velocity and hot air temperature.

Figure $5 \mathrm{~b}$ shows the interactive effect of hot air velocity and hot air temperature on TSC with constant slice thickness and microwave power density at $10 \mathrm{~mm}$ and $6 \mathrm{~W} / \mathrm{g}$, respectively. TSC increased first and then decreased at the hot air velocity and temperature of $2.8 \mathrm{~m} / \mathrm{s}$ and $63.0^{\circ} \mathrm{C}$, respectively. The main reason for this variation was that at the tested levels, the rational increase of hot air velocity and hot air temperature not only shortened drying time but also controlled the temperature of drying materials at a low level, thus improving TSC. However, when hot air velocity and temperature exceeded rational values $\left(H_{v} \geq 2.8 \mathrm{~m} / \mathrm{s}\right.$ and $\left.H_{t} \geq 60^{\circ} \mathrm{C}\right)$, hot air accelerated evaporation rate of water on the surface of drying Chinese yam slices at the initial drying period, causing case hardening. The case hardening was intensified over drying time, which in turn reduced water transfer rate. The reduced water transfer rate centralized a large amount of heat in the interior of drying yams and thus caused a sharp rise in the temperature of the interior of drying yams, decreasing TSC due to the occurrence of Maillard and caramelization reactions.

\section{Optimization and Model Verification}

The optimal condition process for the drying of yam slices using MWHA was determined to obtain maximum RR and TSC. Second-order polynomial models obtained in the study were used for each response to investigate the specified optimum drying condition. These regression models were only valid in the selected experimental domain. All factors including process variables and responses variables were equally weighed. By applying the desirability function method, the optimal conditions were obtained with the slice thickness of $8.5 \mathrm{~mm}$, hot air velocity of $2.5 \mathrm{~m} / \mathrm{s}$, hot air temperature of $61.7^{\circ} \mathrm{C}$, and microwave power density of $5.9 \mathrm{~W} / \mathrm{g}$. Under the optimal conditions, the predicted values for RR and TSC were $1.90 \mathrm{~g} / \mathrm{g}$ and $5.74 \mathrm{~g} / 100 \mathrm{~g}$, respectively, which are very close to the test values (Table 5). The desirability of 0.913 under the optimal conditions further confirmed the validation of models. 
Table 5. Predicted and test values of response variables under optimal conditions.

\begin{tabular}{|c|c|c|c|}
\hline Optimal Drying Conditions & Response Variable & Test Value & Predicted Value \\
\hline $\begin{array}{l}\text { Slice thickness } / 8.5 \mathrm{~mm} \\
\text { Hot air velocity } / 2.5 \mathrm{~m} / \mathrm{s}\end{array}$ & $\mathrm{RR} /(\mathrm{g} / \mathrm{g})$ & 1.83 & 1.90 \\
\hline $\begin{array}{c}\text { Hot air temperature } / 61.7^{\circ} \mathrm{C} \\
\text { Microwave power density } / 5.9 \mathrm{~W} / \mathrm{g}\end{array}$ & $\mathrm{TSC} /(\mathrm{g} / 100 \mathrm{~g})$ & 5.72 & 5.74 \\
\hline
\end{tabular}

\section{Conclusions}

In this work, the optimal conditions of MWHA drying for Chinese yam slices was obtained using RSM. Results showed that the second-order polynomial model with the $R^{2}$ value higher than 0.95 adequately described and predicted the responses RR and TSC under the tested conditions. According to the $p$-values, the effects of variables on RR followed the order: slice thickness $>$ hot air temperature $>$ microwave power density $>$ hot air velocity; and the effects of variables on TSC followed the order: slice thickness $>$ microwave power density $>$ hot air velocity $>$ hot air temperature. The optimal conditions were obtained with the slice thickness of $8.5 \mathrm{~mm}$, hot air velocity of $2.5 \mathrm{~m} / \mathrm{s}$, hot air temperature of $61.7^{\circ} \mathrm{C}$, and microwave power density of $5.9 \mathrm{~W} / \mathrm{g}$. The experimental data and predicted values of response variables were extremely close with a desirability of 0.913 . Therefore, the developed second-order polynomial model is powerful.

Author Contributions: Conceptualization, H.W. and H.Y.; Methodology, H.W.; Software, H.W.; Validation, D.L., and H.W.; Writing-Original Draft Preparation, H.W.; Writing-Review \& Editing, J.L.; Supervision, D.W.; Funding Acquisition, H.Y.

Funding: This research was funded by Heilongiiang Provincial Natural Science Foundation of China (C2015037), China Postdoctoral Science Foundation (2016M601404), and the Young Innovative Talents Project of Heilongjiang Bayi Agricultural University (CXRC2017003).

Conflicts of Interest: The authors declare no conflict of interest.

\section{References}

1. Yang, W.; Wang, Y.; Li, X.; Yu, P. Purification and structural characterization of Chinese yam polysaccharide and its activities. Carbohydr. Polym. 2015, 117, 1021-1027. [CrossRef] [PubMed]

2. Ju, H.-Y.; Zhang, Q.; Mujumdar, A.; Fang, X.-M.; Xiao, H.-W.; Gao, Z.-J. Hot-air Drying Kinetics of Yam Slices under Step Change in Relative Humidity. Int. J. Food Eng. 2016, 12, 783-792. [CrossRef]

3. Chen, Y.-F.; Zhu, Q.; Wu, S. Preparation of oligosaccharides from Chinese yam and their antioxidant activity. Food Chem. 2015, 173, 1107-1110. [CrossRef] [PubMed]

4. Huang, C.-H.; Cheng, J.-Y.; Deng, M.-C.; Chou, C.-H.; Jan, T.-R. Prebiotic effect of diosgenin, an immunoactive steroidal sapogenin of the Chinese yam. Food Chem. 2012, 132, 428-432. [CrossRef] [PubMed]

5. $\quad$ Lin, Y.-P.; Lee, T.-Y.; Tsen, J.-H.; King, V.A.-E. Dehydration of yam slices using FIR-assisted freeze drying. J. Food Eng. 2007, 79, 1295-1301. [CrossRef]

6. Xiao, H.; Yao, X.; Lin, H.; Yang, W.; Meng, J.; GAO, Z. Effect of SSB (superheated steam blanching) time and drying temperature on hot air impingement drying kinetics and quality attributes of yam slices. J. Food Process Eng. 2012, 35, 370-390. [CrossRef]

7. Ju, H.; El-Mashad, H.M.; Fang, X.; Pan, Z.; Xiao, H.; Liu, Y.; Gao, Z. Drying characteristics and modeling of yam slices under different relative humidity conditions. Dry. Technol. 2016, 34, 296-306. [CrossRef]

8. Zhang, Z.; Gao, W.; Li, X.; Jiang, Q.; Xia, Y.; Wang, H.; Huang, L.; Guo, L. Effect of different drying methods on the physicochemical and functional properties of Dioscorea opposita Thunb. starch. Starch-Stärke 2013, 65, 219-226. [CrossRef]

9. Song, X.; Hu, H.; Zhang, B.; Xiaoyong, S.; Hao, H.; Baoling, Z. Drying characteristics of Chinese Yam (Dioscorea opposita Thunb.) by far-infrared radiation and heat pump. J. Saudi Soc. Agric. Sci. 2018, 17, 290-296. [CrossRef]

10. Li, L.; Zhang, M.; Bhandari, B. Influence of drying methods on some physicochemical, functional and pasting properties of Chinese yam flour. LWT 2019, 111, 182-189. [CrossRef] 
11. Zhao, D.; An, K.; Ding, S.; Liu, L.; Xu, Z.; Wang, Z. Two-Stage Intermittent Microwave Coupled with Hot-Air Drying of Carrot Slices: Drying Kinetics and Physical Quality. Food Bioprocess Technol. 2014, 7, 2308-2318. [CrossRef]

12. Tian, Y.; Liang, J.; Zeng, H.; Zheng, B. Microwave Drying Characteristics and Kinetics of Lotus (Nelumbo nucifera Gaertn.) Seeds. Int. J. Food Eng. 2013, 9, 91-98. [CrossRef]

13. Thuto, W.; Banjong, K. Investigation of Heat and Moisture Transport in Bananas during Microwave Heating Process. Processes 2019, 7, 545. [CrossRef]

14. Cao, X.; Zhang, M.; Fang, Z.; Mujumdar, A.S.; Jiang, H.; Qian, H.; Ai, H. Drying kinetics and product quality of green soybean under different microwave drying methods. Dry. Technol. 2017, 35, 240-248. [CrossRef]

15. Motavali, A.; Najafi, G.H.; Abbasi, S.; Minaei, S.; Ghaderi, A. Microwave-vacuum drying of sour cherry: Comparison of mathematical models and artificial neural networks. J. Food Sci. Technol. 2013, 50, 714-722. [CrossRef]

16. Andrés, A.M.; Fito, P.; Heredia, A.; Rosa, E.M. Combined Drying Technologies for Development of High-Quality Shelf-Stable Mango Products. Dry. Technol. 2007, 25, 1857-1866. [CrossRef]

17. An, K.; Zhao, D.; Wang, Z.; Wu, J.; Xu, Y.; Xiao, G. Comparison of different drying methods on Chinese ginger (Zingiber officinale Roscoe): Changes in volatiles, chemical profile, antioxidant properties, and microstructure. Food Chem. 2016, 197, 1292-1300. [CrossRef]

18. Gowen, A.; Abu-Ghannam, N.; Frias, J.; Oliveira, J. Optimisation of dehydration and rehydration properties of cooked chickpeas (Cicer arietinum L.) undergoing microwave-hot air combination drying. Trends Food Sci. Technol. 2006, 17, 177-183. [CrossRef]

19. Gowen, A.; Abu-Ghannam, N.; Frias, J.; Oliveira, J.; Gowen, A. Modeling dehydration and rehydration of cooked soybeans subjected to combined microwave-hot-air drying. Innov. Food Sci. Emerg. Technol. 2008, 9, 129-137. [CrossRef]

20. Pu, G.; Song, G.; Song, C.; Wang, J. Analysis of thermal effect using Coupled Hot-air and Microwave heating at different position of potato. Innov. Food Sci. Emerg. Technol. 2017, 41, 244-250. [CrossRef]

21. Varith, J.; Dijkanarukkul, P.; Achariyaviriya, A.; Achariyaviriya, S. Combined microwave-hot air drying of peeled longan. J. Food Eng. 2007, 81, 459-468. [CrossRef]

22. Talens, C.; Castro-Giraldez, M.; Fito, P.J. Effect of Microwave Power Coupled with Hot Air Drying on Sorption Isotherms and Microstructure of Orange Peel. Food Bioprocess Technol. 2018, 11, 723-734. [CrossRef]

23. Šumić, Z.; Vakula, A.; Tepić, A.; Čakarević, J.; Vitas, J.; Pavlić, B. Modeling and optimization of red currants vacuum drying process by response surface methodology (RSM). Food Chem. 2016, 203, 465-475. [CrossRef] [PubMed]

24. Noshad, M.; Mohebbi, M.; Shahidi, F.; Mortazavi, S.A. Multi-objective optimization of osmotic-ultrasonic pretreatments and hot-air drying of quince using response surface methodology. Food Bioprocess Technol. 2012, 5, 2098-2110. [CrossRef]

25. Erbay, Z.; Icier, F. Optimization of hot air drying of olive leaves using response surface methodology. J. Food Eng. 2009, 91, 533-541. [CrossRef]

26. Kumar, D.; Prasad, S.; Murthy, G.S. Optimization of microwave-assisted hot air drying conditions of okra using response surface methodology. J. Food Sci. Technol. 2014, 51, 221-232. [CrossRef]

27. Šumić, Z.; Tepić, A.; Vidović, S.; Jokić, S.; Malbasa, R. Optimization of frozen sour cherries vacuum drying process. Food Chem. 2013, 136, 55-63. [CrossRef]

28. Yu, H.; Zuo, C.; Xie, Q. Parameter optimization for microwave coupled with hot air drying process of hawthorn slices using response-surface methodology. Int. J. Agric. Biol. Eng. 2015, 8, 121-134. [CrossRef]

29. Alam, M.S.; Amarjit, S.; Sawhney, B.K. Response surface optimization of osmotic dehydration process for aonla slices. J. Food Sci. Technol. 2010, 47, 47-54. [CrossRef]

30. Aksoy, A.; Karasu, S.; Akcicek, A.; Kayacan, S. Effects of Different Drying Methods on Drying Kinetics, Microstructure, Color, and the Rehydration Ratio of Minced Meat. Foods 2019, 8, 216. [CrossRef]

31. Laurence, Y.M.; Sanagi, M.M.; Khan, M.S.; Majid, M.H.A.; Sarjadi, M.S. Effect of drying methods on the colour parameter, rehydration capacity and antioxidant activity of clinacanthus nutans leaves. Malays. J. Chem. $2019,21,62-69$.

32. GB/T 10782-2006. General Rule for Preserved Fruits (In Chinese). Available online: https://books.google.com. ph/books/about/GB_T_10782_2006_Translated_English_of_Ch.html?id=JX0kDwAAQBAJ\&redir_esc=y (accessed on 10 May 2018). 
33. Zhang, J.; Ma, Q.; He, F.; Qu, F.; Li, W. Analysis of moisture and total sugar content of Huizao based on surface images. Int. J. Agric. Biol. Eng. 2017, 11, 238-243. [CrossRef]

34. Cui, X.; Yang, J.; Shi, X.; Lei, W.; Huang, T.; Bai, C. Pelletization of Sunflower Seed Husks: Evaluating and Optimizing Energy Consumption and Physical Properties by Response Surface Methodology (RSM). Processes 2019, 7, 591. [CrossRef]

35. Le, X.D.; Nguyen, M.C.; Vu, D.H.; Pham, M.Q.; Pham, Q.L.; Nguyen, Q.T.; Nguyen, T.A.; Pham, V.T.; Bach, L.G.; Nguyen, T.V.; et al. Optimization of Microwave-Assisted Extraction of Total Phenolic and Total Flavonoid from Fruits of Docynia indica (Wall.) Decne. Using Response Surface Methodology. Processes 2019, 7, 485. [CrossRef]

36. Eren, I.; Kaymak-Ertekin, F. Optimization of osmotic dehydration of potato using response surface methodology. J. Food Eng. 2007, 79, 344-352. [CrossRef]

37. Shi, Q.-L.; Xue, C.-H.; Zhao, Y.; Li, Z.-J.; Wang, X.-Y.; Luan, D.-L. Optimization of processing parameters of horse mackerel (Trachurus japonicus) dried in a heat pump dehumidifier using response surface methodology. J. Food Eng. 2008, 87, 74-81. [CrossRef]

38. Han, Q.-H.; Yin, L.-J.; Li, S.-J.; Yang, B.-N.; Ma, J.-W. Optimization of Process Parameters for Microwave Vacuum Drying of Apple Slices Using Response Surface Method. Dry. Technol. 2010, 28, 523-532. [CrossRef]

39. Giri, S.K.; Prasad, S. Optimization of Microwave-Vacuum Drying of Button Mushrooms Using Response-Surface Methodology. Dry. Technol. 2007, 25, 901-911. [CrossRef]

40. Sharma, G.; Prasad, S. Drying of garlic (Allium sativum) cloves by microwave-hot air combination. J. Food Eng. 2001, 50, 99-105. [CrossRef]

41. Seremet, L.; Botez, E.; Nistor, O.-V.; Andronoiu, D.G.; Mocanu, G.-D. Effect of different drying methods on moisture ratio and rehydration of pumpkin slices. Food Chem. 2016, 195, 104-109. [CrossRef]

(C) 2019 by the authors. Licensee MDPI, Basel, Switzerland. This article is an open access article distributed under the terms and conditions of the Creative Commons Attribution (CC BY) license (http://creativecommons.org/licenses/by/4.0/). 